Poster sessions

Abstract P175 Table 1 Comparison of average air leak over $48 \mathrm{~h}$ and overall chest drain duration by initial air leak reduction (i.e. $<50 \mathrm{ml} / \mathrm{min}$ in 30mins), for each surgical procedure

\begin{tabular}{|c|c|c|c|c|c|c|}
\hline Surgical procedure & $\begin{array}{l}\text { Air leak reduced to } \\
<50 \mathrm{ml} / \mathrm{min} \text { in } 30 \mathrm{mins} ?(\%)\end{array}$ & N (\%) & $\begin{array}{l}\text { Average leak over next } \\
48 \mathrm{hrs} \mathrm{(ml/min)}\end{array}$ & $\begin{array}{l}\text { Significance of } \\
\text { difference ( } p \text { value) }\end{array}$ & $\begin{array}{l}\text { Drain duration } \\
\text { (days) }\end{array}$ & $\begin{array}{l}\text { Significance of } \\
\text { difference ( } p \text { value) }\end{array}$ \\
\hline \multirow[t]{2}{*}{ Lung resection } & $Y$ & $34(38.6 \%)$ & 34.4 & & 5.0 & \\
\hline & $\mathrm{N}$ & $55(61.4 \%)$ & 164.9 & 0.01 & 7.1 & 0.26 \\
\hline Total/Average & & $88(100 \%)$ & 114.4 & & 6.1 & \\
\hline \multirow[t]{2}{*}{ Pleural } & Y & $18(64.3 \%)$ & 9.1 & & 3.00 & \\
\hline & $\mathrm{N}$ & $10(35.7 \%)$ & 196.7 & 0.03 & $9.70^{*}$ & 0.19 \\
\hline Total/Average & & $28(100 \%)$ & 76.4 & & 5.4 & \\
\hline \multirow[t]{2}{*}{ Empyema } & Y & $7(58.3 \%)$ & 9.83 & & 7.0 & \\
\hline & $\mathrm{N}$ & $5(41.7 \%)$ & 1001.4 & 0.08 & 15.4 & 0.12 \\
\hline Total/Average & & $12(100 \%)$ & 423.0 & & 10.5 & \\
\hline
\end{tabular}

with $>50 \mathrm{ml} / \mathrm{min}$ air leak (see Table). The mean air leak over the subsequent $48 \mathrm{~h}$ was significantly different between the groups for patients post-lung resection $(34.4$ vs $164.9 \mathrm{ml} / \mathrm{min}, \mathrm{p}=$ 0.01 ), and post-pleural operation (9.1 vs $196.7 \mathrm{ml} / \mathrm{min}, \mathrm{p}=$ 0.03 ); but not after empyema surgery (9.8 vs $1001.4 \mathrm{ml} / \mathrm{min}$, p $=0.08$ ). The duration of chest drain in situ post-op was lower in the group with early reduction in air leak (but did not reach statistical significance).

Conclusion This sample of post-surgical data suggests that early resolution of air leak is associated with ongoing low air leak (and early drain removal). Equivalent prospective studies are now required in the medical management of pneumothorax to determine whether early physiological measurements can predict outcome.

\section{P176 IATROGENIC PNEUMOTHORAX POST CT-GUIDED LUNG BIOPSY - HOW DO WE MANAGE IT?}

AM Lewis, AA Ionescu. Royal Gwent Hospital, Aneurin Bevan University Health Board, Newport, UK

\subsection{6/thoraxjn-2014-206260.305}

Introduction Iatrogenic Pneumothoraces (IP) are a common complication of computerised tomography (CT)-guided lung biopsy. Management depends on size, underlying lung disease, and symptoms.

The British Thoracic Society (BTS) Guidelines comment that the majority of IPs do not require intervention. If needed aspiration is successful in $89 \%(1)$. Size of pneumothorax is assessed differently by the BTS and The American College of Chest Physicians (ACCP), $(1,2)$. This study reports the management of IP over a 15 -month period.

Methods All IP over 15-months were analysed. Data extraction forms for each IP episode utilised electronic clinical, MDT notes and radiological images.

Results 160 day-case CT-guided lung biopsies were performed. There were 32 IPs, $20 \%$ of all biopsies.

Five IPs were $>2 \mathrm{~cm}$ at hilar level, classified as large by BTS guidance. Fifteen were $>3 \mathrm{~cm}$ apically, described as large by ACCP classification.

There was poor agreement between BTS and ACCP sizing of pneumothoraces, (kappa 0.26).

All BTS-classified large pneumothoraces, and 9(60\%), of ACCP-classified large pneumothoraces required intervention.
Fifteen (47\%) patients with IP, all asymptomatic with pneumothoraces

Nine (28\%) IPs underwent inpatient observation. Three subsequently required intervention, all of which were small at hilar level but large apically, or symptomatic.

Aspiration was performed in 4 patients, one being $>2 \mathrm{~cm}$ at hilar level and all $>3 \mathrm{~cm}$ apically. Two required subsequent tube drainage.

Five (16\%) IPs were treated initially with intercostal chest drainage. Four had pneumothoraces $>2 \mathrm{~cm}$ at hilar level, and the other had a large apical pneumothorax. Only one was symptomatic.

Five patients were initially observed or had simple aspiration but subsequently required tube drainage.

Conclusions Two-thirds of the IPs were managed conservatively. Thirteen percent of patients had aspiration of which three-quarters needed subsequent intervention. Symptoms or FEV1 did not predict need for intervention. The BTS and ACCP criteria for size assessment had poor agreement and clinical judgement was used to decide on treatment.

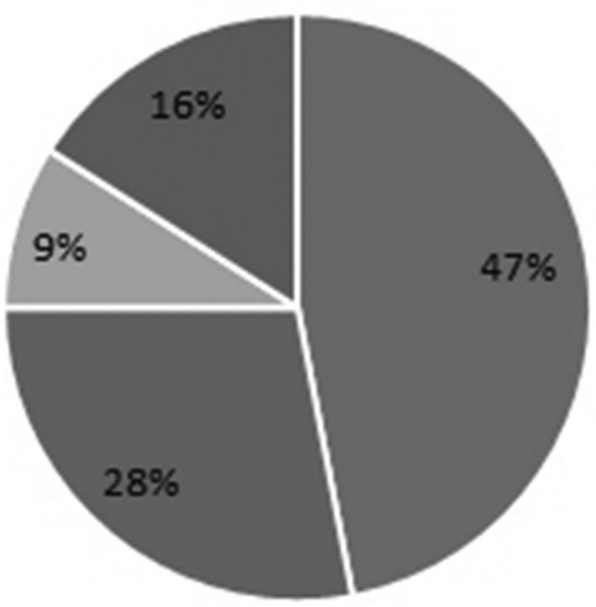

- Discharged " Observed "Aspiration "ICD

Abstract P176 Figure 1 Initial management of pneumothoraces post CT-guided biopsy 